\title{
O Método de Autópsia Psicossocial como Recurso de Investigação acerca do Suicídio
}

\author{
Selena Mesquita de Oliveira Teixeira \\ Universidade de Fortaleza - UNIFOR, Fortaleza, CE, \\ Faculdade Integral Diferencial - DeVry FACID, Teresina, PI, Brasil
}

\begin{abstract}
RESUMO - O objetivo deste artigo é discutir o método de autópsia psicossocial como instrumento de investigação retrospectiva utilizado em estudos aprofundados sobre o suicídio. Optou-se por fundamentar conteúdos referentes aos aspectos estruturais das autópsias psicossociais, bem como acerca das finalidades e possíveis resultados de seu uso. Buscou-se, também, explorar a aplicabilidade, vantagens e limitações do método em questão. Constatou-se a riqueza desse método retrospectivo na realização de estudos que objetivem compreender o suicídio em profundidade, à medida que os resultados possibilitam conhecer em detalhes a atmosfera que envolveu o fenômeno, suas motivações, possíveis causas, fatores psicossociais e aspectos subjetivos associados à morte. Os resultados oportunizam a reunião de informações imprescindíveis para o embasamento de ações eficazes de prevenção ao suicídio.
\end{abstract}

PALAVRAS-CHAVE: autópsia psicológica, autópsia psicossocial, suicídio, prevenção

\section{The Method of Psychosocial Autopsy as a Suicide Investigation Resource}

\begin{abstract}
The aim of this article is to discuss the method of psychosocial autopsy as a retrospective research tool used during in-depth suicide studies. The content related to the structural aspects of psychosocial autopsies was provided with a foundation, as well as the purposes and possible results of its use. Furthermore, the applicability, advantages and limitations of the method in question were explored. The richness of this retrospective method was noted in conducting in-depth studies aimed at understanding suicide, as the results make it possible to know in detail the atmosphere that involved the phenomenon, its motivations, possible causes, psychosocial factors and subjective aspects associated with death. The results allow the gathering of information essential for the foundation of effective actions to prevent suicide.
\end{abstract}

KEYWORDS: psychosocial autopsy, suicide, prevention

O suicídio se constitui como uma grave questão de saúde pública no mundo. Segundo uma perspectiva global, estima-se que o suicídio vitima cerca de um milhão de pessoas por ano. Trata-se de um fenômeno multifatorial e marcado pela complexidade, tendo em vista que é uma construção, não devendo ter sua causa reduzida a apenas um acontecimento específico. O suicídio precisa ser estudado a partir de diversos elementos, incluindo a história de vida do sujeito, eventos circunstanciais, familiares e ambientais, aspectos psicológicos pautados por questões subjetivas, referências culturais e o contexto socioeconômico no qual a pessoa viveu (Cavalcante \& Minayo, 2010).

Este artigo aborda o método de autópsias psicossociais que possibilita, por meio de análise retrospectiva, a identificação dos fatores psicossociais que envolveram casos de suicídio, tornando viável a compreensão do fenômeno. Dessa maneira, ao analisar tais fatores psicossociais, associados ao comportamento suicida, adota-se um enfoque sistêmico que leva em conta as diferentes dimensões humanas e contextos de vida. $\mathrm{O}$ intuito é que a compreensão desses fatores contribua para o desenvolvimento de

\footnotetext{
*E-mail: selenateixeira@hotmail.com
} 
ações preventivas eficazes e para a descoberta de novas possibilidades de atuação do setor de saúde, social e de direitos humanos (Sérvio \& Cavalcante, 2013).

O método da autópsia psicológica foi proposto por Edwin Schneidman, nos Estados Unidos, na década de 1950, evidenciando sua eficácia em diversos contextos: na clínica, no contexto forense e no âmbito da pesquisa sobre o suicídio ( Murthy, Lakshman, \& Gupta, 2010; Miranda \& Tavares, 2014). As autópsias psicossociais ocorrem a partir do depoimento de parentes, amigos ou profissionais que testemunharam um caso de suicídio e acompanharam de perto a trajetória de vida do sujeito que executou o ato.

Este trabalho retrospectivo tem, como objetivo primordial, estimular o resgate da história de vida do sujeito que cometeu suicídio, para posterior identificação das motivações e possíveis causas que levaram à morte autoprovocada. Os resultados da aplicação desse método, em geral, produzem explicações para os seguintes questionamentos: (a) O que ocorreu?; (b) Por que ocorreu?; (c) De que maneira aconteceu? (Shneidman, 2004).

A construção de autópsias psicossociais almeja à ampliação das concepções e compreensões sobre o suicídio. Com base nesse intuito, ainda que Shneidman (2004) nomeasse o seu método como autópsia psicológica, adotava uma visão sistêmica e integral do fenômeno, considerando as peculiaridades de cada caso e a realidade social envolvida (Cavalcante \& Minayo, 2012).
Com o mesmo desígnio, Minayo e Cavalcante (2011) utilizam o termo autópsia psicossocial com o propósito de aclarar as dimensões que o método pretende abarcar e a visão integrada requerida por Shneidman $(1969,1981)$, levando em conta que o suicídio não pode ser determinado por uma causa única, pois parte de uma construção feita ao logo da vida.

Assim, objetiva-se, neste estudo, discutir acerca das autópsias psicossociais como abordagem metodológica que possibilita estudar o suicídio em profundidade. Considerase, como recurso adequado para a análise dos fatores psicossociais que perpassaram o suicídio, a realização de autópsias psicossociais por meio de entrevistas de suicídio (Werlang, 2012).

Diversas publicações científicas ressaltam que a autópsia psicossocial, em casos de suicídio, compreende um completo instrumento de avaliação clínica e pesquisa (Murthy et al., 2010; Minayo et al. 2011; Werlang, 2012). Entretanto, no contexto brasileiro, trata-se de método ainda pouco divulgado, carecendo de novos estudos, à medida que se configura como uma estratégia de avaliação complexa e multidimensional (Werlang \& Botega, 2004).

Sendo assim, a partir da revisão e análise de toda a história de vida do sujeito, torna-se possível idealizar programas de prevenção do comportamento suicida, o que justifica a importância de se estudar com mais afinco essa abordagem metodológica.

\section{O SUICÍDIO ENQUANTO FENÔMENO PSICOSSOCIAL}

O suicídio é um fenômeno complexo e, por essa razão, tem despertado a atenção e o estudo das diversas áreas do conhecimento científico. A característica que marca a complexidade de se estudar o suicídio refere-se à combinação de fatores, que concorrem para um desfecho fatal, isto é, o caráter multifatorial do fenômeno tratado (Cavalcante \& Minayo, 2004; Minayo \& Cavalcante, 2010). Nesse sentido, evidencia-se a importância de se investigar os motivos que levaram a pessoa a tentar suicídio e, sobretudo, conhecer as razões psicológicas que conduziram o sujeito a desistir da propria vida.

Em geral, essas razões são cultivadas ao longo da existência, contemplando seus comportamentos, formas de pensar, traços de personalidade e modos de viver. Razões psicológicas qualificam-se como forças que direcionam a ação, praticada com o intuito de preencher uma necessidade,compreendendo, nesse contexto, a necessidade imediata de interromper a dor psíquica (Minayo \& Cavalcante, 2011; Werlang, Macedo, \& Asnis, 2005).

Nessa perspectiva, frequentemente o suicídio apresentase como o finalizar de uma existência tóxica, uma vida marcada por infortúnios, na qual o autoextermínio é apenas o ponto mais alto do sofrimento psíquico, haja vista que a vida de uma pessoa que comete suicídio é comumente marcada por eventos trágicos, denotando ser o processo construído e multideterminado (Kalina \& Kovadloff, 1983).

Pode-se inferir que o sofrimento atua como obstáculo à visualização de novas possibilidades para superá-lo, as outras opções de enfrentamento são obscurecidas por uma dor intensa e tornam-se imperceptíveis para o sujeito que o experiencia. Logo, a compreensão profunda da pessoa em risco de suicídio torna-se uma questão essencial, levandose em conta que qualquer abordagem preventiva dessa problemática deve considerar os fatores risco e proteção que integram sua construção (Sérvio \& Cavalcante, 2013).

Mediante essas considerações, percebe-se que estudos acerca do suicídio devem eleger uma abordagem metodológica que considere o fenômeno em sua complexidade e oportunize a noção integral do sujeito. Shneidman (1994) e Werlang e Botega (2004) colaboram com essa perspectiva e defendem que o método das autópsias psicossociais é o mais adequado para esse tipo de investigação, pois possibilitam um estudo detalhado e multidisciplinar do suicídio. 


\section{ORIGEM E DETALHAMENTO DO MÉTODO DE AUTÓPSIAS PSICOSSOCIAIS}

O método de autópsias psicossociais iniciou-se como um instrumento de investigação a ser aplicado aos casos de mortes cujos motivos e causas eram questionáveis. Caracteriza-se como uma técnica de pesquisa usada para se descobrir os ensejos da morte em situação duvidosa, a fim de se descartar ou confirmar as opções de suicídio, acidentes e outras mortes violentas (Arco \& Huici, 2005).

Utiliza-se esse método científico para coletar informações a respeito da vida do falecido e sobre os fatores relevantes que perpassaram o suicídio, por meio de uma entrevista retrospectiva. A autópsia psicossocial visa, então, à reconstrução da história do indivíduo da forma mais completa possível, contemplando a reunião de informações sobre o seu modo de vida, aspectos subjetivos associados à morte, fatores psicossociais, ambientais, familiares, médicos e psiquiátricos, além da função que a vítima desempenhou, bem como sua intencionalidade em relação à própria morte (Werlang \& Botega, 2004). Desse modo, trata-se de método retrospectivo que almeja "reconstituir o status da saúde física e mental e as circunstâncias sociais das pessoas que se suicidaram, a partir de entrevistas com familiares e informantes próximos à vítima" (Shneidman, 1981, p. 4).

O referido método surgiu no final da década de 1950, com o propósito inicial de assessorar médicos forenses a investigar casos de mortes com causas confusas. Nesse período, nos Estados Unidos, o chefe do condado de Los Angeles, médico forense Theodore Curphey, encontrou dificuldades de diferenciar as mortes acidentais das mortes por suicídio, solicitando ajuda especializada para investigar as causas imprecisas. Na ocasião, nomeou técnicos do Centro de Prevenção do Suicídio (CPS) de sua cidade para executar tal investigação (Werlang, Macedo, \& Asnis, 2005). Shneidman, Farberow e Litman (1969), como integrantes desse Centro, averiguavam, mediante a realização de autópsias psicológicas, aspectos valiosos que envolviam a morte misteriosa, incluindo características internas e externas do falecido, bem como aspectos que contemplavam a atmosfera do óbito, podendo classificar com maior precisão o registro de suicídio.

Com o propósito inicial de conhecer as razões psicológicas e as motivações externas que impulsionaram um estudante de filosofia a cometer suicídio, Shneidman se debruçou durante seis meses na construção de uma única autópsia. Para isso, investigou em "Autopsy of a Suicidal Mind" todo o contexto de vida do estudante, em entrevistas com pessoas que acompanharam de perto sua vida e morte.
Na ocasião, entrevistou pais, irmãos, ex-esposa, namorada atual e profissionais que o acompanhavam, incluindo psicólogos e psiquiatras.

Os resultados colhidos nessa investigação foram posteriormente compartilhados com especialistas na área e profissionais de saúde mental que estudavam o suicídio, com o intuito de enriquecer a análise do material a partir da integração de diferentes olhares sobre o autoextermínio. Após a análise conjunta do caso, Shneidman inferiu dezoito presunções sobre o suicídio investigado, englobando circunstâncias pessoais, sociais e culturais. A utilização dessa abordagem metodológica colaborou para a consolidação da suicidologia como disciplina científica (Shneidman, 2004).

Litman (1988) e Shneidman (1994) colocam que o principal fator para identificar se uma morte ocorreu por suicídio ou não é verificar as reais intenções da vítima, especialmente se a mesma compreendia que sua ação findaria sua existência física e sua própria morte estaria sendo usada instrumentalmente para resolver problemas de vida. As avaliações retrospectivas permitem verificar as intenções de se matar do falecido.

Esse método caracteriza-se como um modelo de investigação complexo, por examinar concomitantemente aspectos individuais, socioeconômicos, histórico-culturais e populacionais, todos associados ao contexto de ocorrência do suicídio. Devido à exigência de estudos de casos aprofundados, sua utilização ainda se mostra bastante escassa na maioria dos países, incluindo no Brasil (Minayo, Cavalcante, \& Souza, 2006; Minayo et al., 2011).

Em síntese, o método de investigação retrospectiva deve avaliar o contexto social, familiar, econômico e pessoal do falecido e analisar os aspectos psicológicos e singulares do sujeito. Considera-se, também, de fundamental importância, o entendimento do meio cultural no qual o sujeito estava inserido, compreendendo-se o suicídio como fenômeno multifatorial. Sendo assim, o método aqui abordado, também pode ser nomeado de autópsia psicossocial, por considerar o sujeito em seu contexto social (Arenales, Arenales, \& Cruz, 2002; Minayo \& Cavalcante, 2011).

Os resultados, em geral, são estudados por uma equipe multidisciplinar, para que as análises ocorram em profundidade, o que possibilita a análise psicossocial de diferentes dimensões, como as psicológicas, psiquiátricas, sociológicas, antropológicas e históricas. Esse tipo de análise tem como enfoque a interação dessas dimensões e caracteriza o estudo qualitativo acerca do suicídio (Shneidman, 2004). 


\section{APLICABILIDADE DO MÉTODO DE INVESTIGAÇÃO RETROSPECTIVA}

Por se tratar de um método denso e que exige detalhamento na reconstrução das narrativas, considera-se conveniente trabalhar com números reduzidos de casos. Essa estratégia qualitativa de investigação visa à contextualização aprofundada dos acontecimentos de vida e dos eventos que envolveram a atmosfera da morte. Em razão disso, mostra-se essencial no uso desse método, além das entrevistas, uma consulta criteriosa a laudos periciais, prontuários médicos, bem como depoimentos de profissionais de saúde e assistência social que tiveram acesso ao caso, como explicam Cavalcante e Minayo (2012):

Nesse momento, traços psicológicos se articulam com os biográficos, socioeconômicos e culturais. Esse procedimento analítico propicia uma visão holística do tema contrapondo-se à tendência unidimensional de muitos estudos que tratam as causas do suicídio como tópicos isolados e não como fatores múltiplos, interativos e que competem entre si, tornando as pessoas progressivamente mais vulneráveis. (p. 2048)

Para elaboração de entrevistas de suicídio, mostra-se necessário um conhecimento extenso sobre o tema, além de consultas a trabalhos anteriores que utilizaram o método. Para contextualização das histórias reconstituídas, sugere-se o recolhimento de dados socioantropológicos da localidade onde o suicídio ocorreu, com a finalidade de conhecer como vive aquela população específica, incluindo formação social, cultural e econômica (Minayo \& Cavalcante, 2011).

A entrevista deve ser semiestruturada, entretanto, precisa seguir um protocolo que assegure a existência dos dados populacionais da vítima, a exemplo da idade no momento da morte, local de residência, ocupação, estado civil, religião, entre outros. Deve haver, também, história clínica, pessoal e social do sujeito e, sempre que possível, a análise de documentos pessoais, policiais, acadêmicos e hospitalares. Informações de outras fontes disponíveis também poderão ser úteis, como as oriundas de processo penal, cartas, gravações, etc. Em suma, deve existir a reconstrução da vida dessas pessoas com detalhamento dos períodos de crise e sofrimento, além da averiguação a respeito da maneira como a vítima interagia socialmente e dentro da própria família (Arco \& Huici, 2005; Werlang et al., 2005).

Shneidman (1981) sugere que, além das informações sociodemográficas e os detalhes sobre a morte, é necessário recaptular os antecedentes da pessoa que cometeu suicídio, especialmente em relação à maneira como estabelecia suas relações interpessoais. Caballero et al. (2010) ressaltam que devem ser investigadas tentativas anteriores de suicídio, bem como se há histórico de suicídio na família. Também deve haver uma avaliação sobre o estado mental que precedeu o suicídio.

Werlang e Botega (2004) investigaram a aplicabilidade e validade de uma entrevista semiestruturada para autópsia psicossocial em casos de suicídio. Estudaram a confiabilidade de tal método a partir de uma amostra de 42 sujeitos, associados a 21 casos de suicídio. Nessa pesquisa, foram investigados quatro tópicos essenciais na utilização dessa abordagem metodológica: fatores precipitadores ou estressores, motivação, intencionalidade e letalidade. Obtiveram um significativo grau de concordância entre avaliadores. Concluíram que o instrumento é de alta confiabilidade no que se refere a caracterizar mortes de causa duvidosa, desde que os informantes estejam dispostos a contribuir.

Cavalcante e Minayo (2004) e Minayo, Cavalcante e Souza (2006) asseguram a validade do método, ressaltando que o ponto forte desse instrumento de investigação retrospectiva está na contextualização dos dados, que amplia a possibilidade de mostrar aspectos que grandes estudos epidemiológicos ou populacionais excluem. Cavalcante, Minayo e Mangas (2013), em seu estudo, analisaram diferentes faces da depressão associadas a suicídio em idosos, fazendo uso de autópsias psicossociais.

As autoras elaboraram um roteiro de entrevista adaptado e descrito em estudos anteriores (Minayo \& Cavalcante, 2011). O método foi executado por meio de três instrumentos: ficha de identificação pessoal e social do idoso que cometeu suicídio e dados gerais do informante; genograma da família da vítima, a fim de reconstituir as características predominantes da dinâmica familiar, ademais para identificar alianças, conflitos, rede de relações, acontecimentos críticos em três gerações e o padrão de morbidade ou mortalidade associado ao suicídio e entrevista semiestruturada para detalhar o estado mental, descrever situações associadas ao comportamento suicida e possíveis motivações, reconstituindo o suicídio e a gravidade de fatores que o envolveu, compreendendo seu impacto na família e os problemas que a família enfrenta atualmente (Cavalcante et al., 2011).

Rojas et al. (1998) alegam que esse tipo de instrumento tem como embasamento aspectos que envolvem a pesquisa psicológica no que se refere à utilização de entrevistas em psicologia clínica e social, como também faz uso dos métodos de investigação criminológica, à medida que estuda, da maneira mais completa possível, a cena do crime e os fatores implicados no ocorrido e comumente inclui o modo de perpetração, os laudos periciais e toda a atmosfera da morte.

Ponderando-se que, a maior parte do que se sabe sobre fatores de risco e proteção agregados ao suicídio vem de autópsias psicossociais (Beeston, 2006; Conwell \& Thompson, 2008), releva ilustrar como os resultados desse método se apresentam, além de aclarar a riqueza das histórias reconstituídas, abordando estudos já realizados que o utilizaram. 


\section{CASO ILUSTRATIVO DO MÉTODO}

Optou-se por apresentar a descrição resumida de um caso de suicídio (Sérvio \& Cavalcante, 2013), a fim de facilitar o entendimento acerca da profundidade dos resultados que esse método retrospectivo possibilita. Para tanto, será apresentado trechos das narrativas coletadas através de uma entrevista em profundidade. Os recortes fazem parte do banco de dados de uma pesquisa multicêntrica desenvolvida no Brasil, coordenada por Cecília Minayo e realizada por pesquisadores do Centro Latino Americano de Estudos de Violência e Saúde Jorge Careli (CLAVES/ FIOCRUZ). A referida pesquisa foi intitulada: É possível prevenir a antecipação do fim? Suicídio de idosos no Brasil e a possibilidade de atuação do setor saúde. O método foi aplicado no estudo de 51 casos de idosos que morreram por suicídio em dez cidades brasileiras (Cavalcante \& Minayo, 2012; Minayo, Grubits, \& Cavalcante, 2012).

Para entrevista em profundidade descrita a seguir, três instrumentos foram utilizados: (1) ficha de identificação pessoal e familiar da pessoa que morreu por suicídio; (2) genograma, a fim de delinear as relações e laços familiares e de se situar os integrantes da família mencionados a história reconstituída; (3) roteiro de entrevista semiestruturada para autópsias psicossociais estruturados com os seguintes eixos: caracterização social, retrato e modo de vida, descrição do suicídio e da atmosfera que o acompanhou, estado mental do idoso nos momentos que antecederam o evento e imagem da família antes, durante e depois do ato fatal. A breve ilustração narra a história de uma idosa (64 anos), identificada pelo nome fictício de Antônia, natural de uma cidade do nordeste brasileiro.

Quando criança, Antônia foi vítima de meningite, da qual resultou perda total da audição, sequela comum nesse quadro clínico. Foi encaminhada ao Rio de Janeiro com o propósito de ser submetida a um tratamento mais especializado. Continuou morando nessa cidade por muitos anos, onde vivia como interna em uma escola para crianças especiais, na qual permaneceu até concluir os estudos. Quando ainda morava no Rio de Janeiro, foi noiva durante um pequeno período, entretanto, o noivo morreu em um acidente de carro. Após a interrupção trágica do relacionamento, Antônia permaneceu o resto de sua vida solteira.

Após a formatura, retornou para sua cidade natal e ocupou um cargo de destaque na Secretaria Estadual de Educação. Depois de anos de dedicação, obteve sua aposentadoria, única fonte de renda de que dispunha para viver. Antônia destinou muito tempo de sua vida ao cuidado dos pais e, após a morte do casal, evidenciou sentir um sofrimento muito intenso. Posteriormente a essa perda, os familiares venderam a casa e dividiram o dinheiro entre os irmãos. Nesse período, Antônia ficou morando sozinha em uma casa alugada. Alguns meses depois, por queixar-se da solidão, foi morar com a sobrinha.
$\mathrm{Na}$ maior parte do tempo, a idosa permanecia com o semblante fechado, isolava-se, além de ficar constantemente em silêncio. Em geral, chorava compulsivamente, sem motivos aparentes. Seu comportamento mais marcante eram ações auto-lesivas, como se cortar com tesouras. Desde muito jovem, Antônia já pensava em cometer suicídio e iniciou tratamento psiquiátrico quando fez a primeira tentativa. Alegava para os familiares que sentia um vazio interior muito grande, por nunca ter encontrado motivos para ser feliz, além de não enxergar possibilidades para isso, especialmente após a perda dos pais.

Nos últimos anos de vida mostrava-se confusa, esquecida e dizia sentir alguém soprando próximo aos seus ouvidos. Usava remédio para controlar a doença de Alzheimer, indicado pelo psiquiatra. Nos meses que antecederam o suicídio, a idosa foi avaliada pelo psiquiatra, que recomendou não a deixar sozinha e esconder facas ou outros objetos com os quais pudesse realizar as tentativas. Antônia não era acompanhada por psicólogos.

Depois de diagnosticada com Alzheimer, fez tentativas de suicídio mais frequentes e parecia não querer mais viver. No período que antecedeu o suicídio, a idosa parecia confusa, denotando alteração no fluxo do pensamento. Há muitos anos vivia deprimida, com comportamentos que oscilavam entre fases de agitação e tristeza. Demonstrava desespero quando tinha problemas financeiros, o que acontecia com assiduidade. No período do óbito, estava aposentada e a renda estava bastante reduzida.

Em dezembro de 2005, entre natal e ano novo, a idosa fez outra tentativa de maior gravidade, sendo levada ao psiquiatra após esse episódio. Nessa mesma época, a família organizou uma viagem para o litoral do Nordeste na tentativa de ajudá-la a superar o sofrimento. Na investigação do histórico de suicídio na família da idosa, foram identificados dois casos, sendo uma prima da família paterna e outro caso não especificado ocorrido na família materna. Depois da morte de Antônia, um sobrinho (Bruno) que residia com ela fez uma tentativa de suicídio. O mesmo ficou recebendo a pensão dela até completar a maioridade.

No dia em que cometeu suicídio, realizou atividades comuns à sua rotina - fez toda a limpeza da casa e, em seguida, almoçou com o sobrinho Bruno. Minutos antes do suicídio, o sobrinho assistia à televisão e a idosa escrevia sentada à mesa, na mesma sala. Caminhando próximo a tia, Bruno conseguiu ler a frase "a culpa é toda minha" e quando ela percebeu que ele havia lido, levantou-se, amassou o papel e o colocou no bolso da bermuda. Pouco depois, a idosa avisou que iria tomar banho, ligou o chuveiro e manteve a porta aberta. Logo em seguida, Bruno ouviu um barulho muito alto e correu em direção ao banheiro, encontrando o corpo da idosa carbonizado.

O sobrinho ainda tentou jogar água no corpo da idosa usando uma ducha, mas logo percebeu que já havia falecido. 
Minutos após o ocorrido, os vizinhos prestaram ajuda ao jovem, que ficou bastante abalado. Os familiares procuraram por toda a casa a mensagem escrita pela vítima antes do seu óbito, porém não a encontraram, presumindo, assim, que o bilhete havia sido queimado dentro do bolso da bermuda. Os familiares mais próximos da idosa receberam apoio dos outros parentes, contudo, não buscaram auxílio profissional. Além da assistência ofertada por parentes e amigos, nenhuma rede de apoio foi identificada.

A reconstrução narrativa possibilitada pela autópsia psicossocial evidencia a consistência do instrumento, bem como credibilidade e profundidade do método. $\mathrm{O}$ ponto forte desse método é a contextualização dos dados e diversidade de perspectivas e interlocutores direcionados a um mesmo fenômeno, além das várias fontes de informações que proporcionam a qualidade e aprofundamento das narrativas recolhidas. O modo interdisciplinar e interinstitucional pelo qual as informações são coletadas reforçam a confiabilidade do seu uso em estudos que consideram a complexidade e o caráter multifatorial do fenômeno do suicídio (Cavalcante \& Minayo. 2012).

A apresentação do caso exemplifica o nível de detalhamento das informações extraídas de um estudo que fez uso do método de autópsias psicossociais. Considerando que a identificação dos fatores associados ao suicídio, em geral, são decorrentes de estudos que utilizaram autópsias psicossociais, faz-se necessário uma exploração mais aprofundada desse método como recurso de investigação acerca do suicídio (Conwell \& Thompson, 2008; Hjelmeland, Dieserud, Dyregros, Knizek, \& Leenars, 2012). Tais resultados poderão indicar os caminhos que necessitam ser percorridos na pesquisa, na assistência e nas políticas públicas, no que tange a formas mais seguras para avaliar o risco e, posteriormente, manejar adequadamente a pessoa em crise suicida, ofertando cuidados globais.

\section{VANTAGENS E LIMITAÇÕES DO USO DE AUTÓPSIAS PSICOSSOCIAIS}

Shneidman (1999) destacou que os benefícios dos resultados de autópsias psicológicas se estendem para além da descoberta das causas da morte, pois oferecem condições para a identificação precoce de pistas diretas ou indiretas do suicídio que ainda está para acontecer. Sendo assim, por meio da compreensão profunda dos aspectos psicossociais que contemplaram um suicídio específico, torna-se possível a identificação de fatores de risco e correlatos sociodemográficos do suicídio. Desse modo, a riqueza do método não está em fornecer um único tipo de análise dos casos, mas em apresentar diferentes perspectivas sobre a morte e a intenção de morrer.

Outras vantagens também podem ser apontadas na utilização desse método, considerando-se que, usualmente, a efetivação de um suicídio faz com que familiares e amigos tomem para si a responsabilidade por não terem impedido o sofrimento que o impulsionou ou mesmo não ter percebido a possibilidade do ato vir a ocorrer. Sendo assim, o sofrimento natural do enlutado pode ser intensificado pela culpa, que, em geral, envolve casos de suicídio, configurando um período de alto risco para novas ocorrências de autoextermínio, sobretudo se o objeto perdido for uma pessoa próxima que cometeu suicídio (Cassorla, 2005).

Os benefícios referentes à utilização desse método de investigação relacionam-se, primeiramente, ao efeito terapêutico que as entrevistas aplicadas podem proporcionar aos informantes, cuja proximidade do suicida faz com que estejam vivenciando um momento de intensa dor, uma vez que a morte por suicídio, mesmo anunciada, tende a produzir um efeito devastador em todas as pessoas de seu convívio (Werlang et al., 2005).

$\mathrm{O}$ efeito terapêutico da entrevista mostra-se evidente em estudos anteriores. Nesse sentido, adota-se como argumento que a entrevista retrospectiva, além de possibilitar os aspectos necessários para a compreensão do que aconteceu, oferece abertura para que o sujeito compreenda a própria dor ao se ouvir, podendo, também, contribuir para a elaboração do luto (Sérvio \& Cavalcante, 2013; Werlang et al., 2005).

O momento da entrevista também equivale a um espaço facilitador para desabafar e expressar sentimentos, bem como para responder a perguntas que ainda afligem as pessoas próximas à vítima, produzindo esclarecimentos sobre um tema ainda tratado como tabu na sociedade atual. Em muitos casos, as reflexões compreensivas realizadas nesses momentos colaboraram para melhor elaboração interna dos entrevistados (Cavalcante \& Minayo, 2012).

O tabu que envolve o suicídio constitui uma das dificuldades para o estabelecimento da fidedignidade das informações acessadas por meio de autópsias psicossociais, à medida que algumas questões podem ficar obscuras por conta da vergonha, preconceito, rancor ou culpa associados a essas recordações. Essas fragilidades do método podem ser significativamente amenizadas com a preparação adequada dos investigadores e a diversificação dos interlocutores (Cavalcante \& Minayo, 2012).

Destarte, a escuta empática dos sujeitos entrevistados amplia a fidedignidade e a coerência da história reconstituída. Esse tipo de escuta convoca a uma qualificação e preparação prévia do investigador, incluindo a familiaridade com o método e a percepção do suicídio enquanto fenômeno complexo e multicausal (Conner et al., 2012). Entretanto, quando não há essa preparação, o pesquisador poderá deparar-se, especialmente, com dificuldades para o manejo emocional do entrevistado, sentindo-se, inclusive, afetado emocionalmente pelo discurso do sujeito (Cavalcante \& Minayo, 2012). 
Botello, Noguchi, Sathyavagiswaran, Weinberger e Gross (2013) apontam que os problemas metodológicos mais comuns na autópsia psicossocial são a identificação das pessoas e obtenção do aceite dos informantes para cada caso acessar outras fontes de informação confiáveis, questões particulares referentes aos familiares e a realização de uma análise aprofundada das narrativas coletadas.

Ademais, as maiores limitações dos estudos com autópsias psicossociais consistem em como analisar as discrepâncias dos relatos. Para isso, entende-se a importância de um olhar hermenêutico dialético no momento da análise, à medida que permitirá um comprometimento sistemático com a compreensão de um fenômeno, apreciando-se, em primeira instância, suas particularidades. Com esse olhar, percebe-se o que há além daquilo que foi escrito no texto ou manifestado em palavras, pois os acontecimentos e, principalmente, a linguagem, não são compreensíveis por si mesmos (Azevedo, 2004; Minayo et al., 2011).

Outra maneira de se minimizar o risco de equívocos nas interpretações consiste em realizar a análise em grupo, principalmente quando a equipe estiver formada por profissionais de diferentes áreas. Em síntese, acredita-se que trabalhar com várias fontes de coleta de informações, realizar mais de uma entrevista por informante, diversificar os interlocutores e realizar a entrevista em dupla com outro pesquisador, são fatores que ampliam a confiança nas informações recolhidas (Cavalcante \& Minayo, 2012).

Por fim, esse tipo de investigação requer manejos delicados e um olhar diferenciado para as questões psicológicas e sociais, necessário a qualquer pesquisador que utilize o método e, sobretudo, ao pesquisador psicólogo, haja vista que este foi formado para atuar nessas questões. Além de contribuir para enfraquecer o tabu que perpassa o suicídio, o pesquisador psicólogo, em anuência com a sua formação, poderá identificar demandas emocionais e o risco de suicídio no entrevistado e, a partir do identificado, realizar os encaminhamentos necessários, contribuindo para a prevenção do suicídio.

\section{CONSIDERAÇÕES FINAIS}

Ponderando-se os aspectos constituintes e os objetivos dessa abordagem metodológica, pode-se inferir que a investigação retrospectiva de todos os aspectos sugeridos pela literatura permite não somente distinguir uma morte por suicídio de outras mortes violentas, mas principalmente oportunizar a identificação de fatores de riscos e correlatos sociodemográficos do suicídio, cujos resultados visam gerar estratégias destinadas à sua prevenção. Nesse sentido, é possível afirmar que as autópsias psicossociais compreendem uma valiosa ferramenta para o estabelecimento de políticas e ações preventivas do suicídio.

Esse método de investigação também se torna enriquecedor, à medida que o profissional preparado poderá oferecer condições essenciais para uma melhor elaboração do luto, tendo em vista que a entrevista com familiares em sofrimento psíquico equivale a um espaço terapêutico quando se estabelece uma escuta autêntica, bem como quando proporciona que se fale da morte trágica de alguém próximo, pois, assim, abre-se, também, condições de acolhimento da dor e elaboração de sentimentos nocivos. Além do apoio emocional, nessa circunstância, o entrevistado poderá obter benefícios referentes a recomendações aos serviços de saúde e encaminhamentos à rede de atenção psicossocial.

Em suma, conclui-se que o aspecto mais relevante na utilização das autópsias psicossociais é a obtenção e análise de dados contextualizados, por considerar, sobretudo, o suicídio enquanto fenômeno complexo e multicausal, acreditando que nunca deve ser investigado de forma isolada, pois a experiência do sofrimento psíquico, apesar de singular, é estabelecida dentro de um contexto, não podendo ser entendida separada desse.

\section{REFERÊNCIAS}

Arco J. N., \& Huici, T. (2005). El uso de la autopsia psicológica forense em el proceso penal. Indentidad Jurídica, 1, 235-242. Retrived from http://buscandoanimo.org/ Descargas/autopsia/03_autopsia\%2520psicologica\%20-\%20 $\mathrm{Nu} \%$ F1ez\%20de\%20Ärco.pdf

Arenales L., Arenales, N. H. B., \& Cruz, J. P. (2002). Autópsia psicológica em adolescente suicida: Relato de caso. The International Journal of Psychiatry, 7(5). Retrived from http:// www.polbr.med.br/ano02/artigo0502_b.php

Azevedo, M. A. (2004). Informação e interpretação: Uma leitura teórico-metodológica. Perspectivas em Ciências da Informação, 9(2), 122-133. Retrieved from http:// portaldeperiodicos.eci.ufmg.br/index.php/pci/article/view/354
Botello, T., Noguchi, T., Sathyavagiswaran. L., Weinberger, L. E., \& Gross, B. H. (2013). Evolution of the psychological autopsy: Fifty years of experience at the Los Angeles County Chief Medical Examiner - Coroner's Office. Journal of Forensic Sciences, 58(4), 924-926. https://doi.org/10.1111/15564029.12138

Beeston, D. (2006). Older people and suicide. Stokeon Trent, UK: Centre For Ageing and Mental Health, Staffordshire University. García-Caballero, A., Recimil, M. J., Touriño. R., García-Lado, I., Alonso, M. C., Werlang, B., ... Bendaña, J. M. (2010). Adaptation and validation of the semi-structured interview for psychological autopsy (SSIPA) in Spanish. Actas Espanolas de Psiquiatria., 38(6), 332-339. Retrieved from https://medes. com/publication/63341 
Cassorla, R. M. S. (2005). O que é suicídio. São Paulo: Brasiliense.

Cavalcante, F. G., \& Minayo, M. C. S. (2004). Organizadores psíquicos e suicídio: Retratos de uma autópsia psicossocial. In P. Almeida (Org.), O mosaico da violência (pp. 371-431). São Paulo: Vetor.

Cavalcante, F. G., \& Minayo, M. C. S. (2012). Autópsias psicológicas e psicossociais de idosos que morreram por suicídio no Brasil. Ciência \& Saúde Coletiva, 17(8), 1943-1954. Retrieved from https://www.scielosp.org/scielo.php?pid=S1413$81232012000800002 \&$ script $=$ sci arttext\&tlng=en

Cavalcante, F. G., Minayo, M. C. S., \& Mangas, R. M. (2013). Diferentes faces da depressão no suicídio em idosos. Ciência \& Saúde Coletiva, 18(10), 2985-2994. Retrieved from https://www.scielosp.org/scielo.php?pid=S1413$81232013001800023 \&$ script $=$ sci arttext\&tlng $=$ en

Conner, K. R., Beautrais, A. L., Brent, D. A., Conwell, Y., Philiips, M. R., \& Schneider, B. (2012). The next generation of psychological autopsy studies: Part.2. Interview procedures. Suicide and Life-Threatening Behavior, 42(1), 86-103. https:// doi.org/10.1111/j.1943-278X.2011.00073.x

Conwell, Y., \& Thompson, C. (2008). Suicidal behavior in elders. Psychiatric Clinics of North America, 31, 333-356. https://doi. org/10.1016/j.psc.2008.01.004

Hjelmeland, H., Dieserud, G., Dyregrov, K., Knizek, B., \& Leenaars, A. A. (2012). Psychological autopsy studies as diagnostic tools: Are they methodologically flawed? Death Studies, 36(7), 605626. https://doi.org/10.1080/07481187.201 1.584015

Rojas, I. A. J., Rodríguez, M. L. M., Sánchez, C. A. G., Gómez, D. A. V., Mora, D. A. J., Rodríguez, M. E. C., \& Navarro, G. A. (1998). Análisis del suicidio a través de la autopsia psicológica. Revista Colombiana de Psiquiatría, 27(3), 197-211. Retrieved from http://psiquiatria.org.co/ web/wp-content/uploads/2012/04/VOL-27/3/Analisis\%20 del $\% 20$ suicidio $\% 20 \mathrm{a} \% 20$ trav $\%$ C3\%A9s\%20de $\% 201 \mathrm{a} \% 20$ autopsia\%20psicol\%C3\%B3gica.pdf vista-colombiana-depsiquiatria/volumen-27-n-3-ano-1998/

Kalina, E., \& Kovadloff, S. (1983). As cerimônias da destruição. Rio de Janeiro: Francisco Alves.

Litman, R. E. (1988). Psychological autopsies, mental illness and intention in suicide. In J. L. Nolan (Ed), The suicide case: Investigation and trial of insurance claims (pp. 69-82). Chicago: Tort and Insurance Practice Section American Bar Association.

Minayo, M. C. S., \& Cavalcante, F. G. (2011). É possível prevenir a antecipação do fim? Suicídio de Idosos no Brasil e possibilidades de atuação do setor saúde (Projeto de pesquisa). Rio de Janeiro: Claves; Fiocruz.

Minayo, M. C. S., \& Cavalcante, F. G. (2010). Suicide in elderly people: A literature review. Revista de Saúde Pública, 44(4), 750-757. http://dx.doi.org/10.1590/S003489102010000400020

Minayo, M. C. S., Cavalcante, F. G., \& Souza, E. R. (2006). Methodological proposal for studying suicide as a complex phenomenon. Caderno de Saúde Pública, 22(8), 15871596. Retrived from https://www.scielosp.org/pdf/csp/2006. v22n8/1587-1596/en

Minayo, M. C. S., Grubits, S., \& Cavalcante, F. G. (2012) Observar, ouvir, compartilhar: trabalho de campo para autópsias psicossociais. Ciência \&. Saúde Coletiva, 17(8), 2027-2038.
Retrived from https://www.scielosp.org/article/csc/2012. v17n8/2027-2038/

Miranda, T. G., Tavares M. (2014). Autópsia psicológica: Compreendendo casos de suicídio e o impacto da perda (Dissertação de mestrado). Programa de Pós-Graduação em Psicologia Clínica e Cultura, Instituto de Psicologia, Universidade de Brasília, Brasília, DF, Brasil.

Murthy, V., Lakshman, V., \& Gupta, M. (2010). Psychological Autopsy- A review. Journal of Pundajab Acadêmy of Forensic Medicine Toxicology, 10(2), 101-103.

Sérvio, S. M. T., \& Cavalcante, A. S. (2013). Retratos de autópsias psicossociais sobre suicídio de idosos em Teresina. Psicologia: Ciência e Profissão, 33(Núm. Esp.), 170-181. Retrieved from https://repositorio.observatoriodocuidado.org/handle/ handle/139

Shneidman, E. S. (1969). Suicide, lethality and the psychological autopsy. In E. S. Shneidman, \& M. Ortega (Eds.), Aspects of depression (pp. 225-249). Boston: Little Brown.

Shneidman, E. S. (1981). The psychological autopsy. Suicide and Life Threatening Behavior, 11(4), 325-340. http://dx.doi. org/10.1111/j.1943-278X.1981.tb01009.x

Shneidman, E. S. (1994). Definition of suicide. New Jersey: Aronson.

Shneidman, E. S. (1999). Perturbation and lethality: A psychological approach to assessment and intervention. In D. G. Jacobs (Ed.), The Harvard Medical School guide to suicide assessment and intervention (pp. 83-97). San Francisco: Jossey-Bass.

Shneidman, E. S. (2004). Autopsy of a suicidal mind. New York, NY: Oxford University Press.

Shneidman, E. S., Farberow, L., \& Litman, R. E. (1969). El Centro de Prevencion del Suicidio. In N. L. Farberow \& E. S. Shneidman (Eds.), Necesito ayuda! Un studio sobre el suicidio y su prevención (pp. 6-19). Mexico: La Prensa Medica Mexicana.

Werlang, B. G., \& Botega, N. J. (2003). A semi-structured interview for psychological autopsy in suicide cases. Revista Brasileira de Psiquiatria, 25(4), 212-219. http://dx.doi.org/10.1590/ S1516-44462003000400006

Werlang, B. S. G., Macedo, M. M. K., \& Asnis, N. (2005). Entrevistas retrospectivas: Autópsia psicológica. In L. K. Carrasco, \& M. M. K. Macedo (Orgs.), (Con)Textos de entrevista: Olhares diversos sobre a interação humana (pp. 195-206). São Paulo: Casa do Psicólogo.

Werlang, B. S. G. (2012). Autópsia Psicológica: importante estratégia de avaliação retrospectiva. Ciência \& Saúde Coletiva, 17(8), 1955-1962; 2012. Retrived from https://www.scielosp. org/scielo.php?pid=S1413-81232012000800003\&script=sci_ arttext\&tlng=pt 